\title{
Preparing Students for Global Citizenship: The Effects of a Dutch Undergraduate Honors Course
}

\author{
Ingrid W. Schutte, ${ }^{1,2}$ Elanor Kamans, ${ }^{1,2}$ Marca V. C. Wolfensberger, ${ }^{1,2}$ and Wiel Veugelers ${ }^{1,2}$ \\ ${ }^{1}$ Hanze University of Applied Sciences, Groningen, Netherlands \\ ${ }^{2}$ University of Humanistic Studies, Utrecht, Netherlands \\ Correspondence should be addressed to Ingrid W. Schutte; i.w.schutte@pl.hanze.nl
}

Received 16 February 2017; Revised 12 June 2017; Accepted 2 July 2017; Published 27 August 2017

Academic Editor: Seokhee Cho

Copyright (c) 2017 Ingrid W. Schutte et al. This is an open access article distributed under the Creative Commons Attribution License, which permits unrestricted use, distribution, and reproduction in any medium, provided the original work is properly cited.

Using a mixed method approach, this case study investigates effects on the participating students $(N=25)$ of an undergraduate honors course in the Netherlands, aimed at global justice citizenship. Knowledge about effects of global citizenship courses is still limited. The Ethical Sensitivity Scale Questionnaire and the Global Citizenship Scale were used in a pre- and posttest design to measure possible development in the moral and civic domain among the participants of the course. In the qualitative part, deductive content analyses of students' work and students' written reflection on the course, utilizing the theory-based curriculum guidelines Global Justice Citizenship Education, were performed. In addition, a follow-up blog and interview were analyzed to learn students' perception on the effects of the course after half a year. Quantitative results show increased ethical sensitivity as well as global civic engagement and global competence among the participants. Qualitative results point in the same direction and provide deeper insights in the content of students' learning and the perceived impact of the course on their attitudes and behavior. Results are discussed in relation to theory on justice-oriented global citizenship and honors pedagogies.

\section{Introduction}

Preparing undergraduate honors students for their role as citizens of the world is an important task in higher education, given the challenges global society faces [1]. Furthermore, research indicates an above-average interest among honors students in moral issues and the wider world (see $[2,3]$ for a review). Nevertheless, global citizenship receives little attention in higher education and few studies consider the effects of global citizenship education on undergraduates [4]. It has been argued that such programs enable them to lead a responsible and moral life [5]. As discussed by Colby et al. [4], this effect has been demonstrated for service learning, which combines community service with academic learning and personal development. For example Lee et al. [2] found that gifted high-school students had an enhanced awareness of civic issues, increased motivation to engage in social issues in their communities, and new understanding and respect for diversity after a three-week service learning program.
In this study, we connect to the justice-oriented approach of global citizenship that includes a desire to improve society [6].

We conceptualize global citizenship similarly to Westheimer and Kahne's justice approach to global citizenship [7], which implies that "global citizens" take informed action based upon insights in structural causes of global injustice or sustainability issues. Next to this, our conceptualization of global citizenship includes a global approach to citizenship, as, in this globalized world, justice and sustainable issues unmistakably contain a global dimension. This global dimension is connected to Nussbaum's moral cosmopolitism [8,9], especially regarding the abilities to think as citizen of the world and to imagine what it would be like to be in the position of someone quite different from yourself.

In the light of this conceptualization of global citizenship and based on literature about (global) justiceoriented citizenship education, curriculum guidelines were developed for the knowledge, moral, and social domain. A learning environment that combines elements from these 
three domains acknowledges the needs of gifted students [10-12]. We call these curriculum guidelines Global Justice Citizenship Education (GJCE). For an overview, see Table 1. In short, these curriculum guidelines concern the following.

Knowledge Domain. In the knowledge domain, the guidelines are (1) gaining historical (root causes of injustice) insights. The historic dimension offers insight in the societal context in which the issue developed $[7,13,14]$. (2) Seeing localglobal connections, as students should understand the global dimension of their own actions and the interdependence between places in the world [15]. (3) Focus on one global justice issue instead of gaining more superficial broader knowledge (see Davies et al. [14] on exploring issues) as narrowing the focus allows one to grasp the social, political, and economic structures that underlie injustice and power differences.

Moral Domain. In the moral domain, two curriculum guidelines were formulated. (1) Develop ethical and intercultural sensitivity [16-18]. Ethical sensitivity relates to the ability to take the perspective of "the other," to pay attention to the welfare of others, and to recognize ethical dilemmas [19]. When encountering people with other cultural backgrounds, students need intercultural sensitivity, the ability to notice and experience cultural difference $[17,18]$. Ethical and intercultural sensitivity relate to one of the guiding aims in Nussbaum's' view on world citizenship: being able to understand the world "from the point of view of the other" ([8, p. 11], [20]). (2) Recognize (own) values and critically reflect on mainstream thinking [13]. The first is about recognizing values behind statements, ideas, and perspectives and evaluating how they relate to students' own values [13]. The second skill is critically reflecting on values, especially on "mainstream" thinking related to the dominant neoliberal ideology. This is important because neoliberal ideology highly impacts all aspects of education [21] and historically grown power differences lead to problematic assumptions in the western world about, for instance, "progress."

Social Domain. Regarding the social domain, the two guidelines are (1) contact people with different socioeconomic positions, cultural backgrounds, and life chances. Such contacts can yield new insight in oneself and one's biases [22] and (2) get to know positive role models: active and socially engaged people with both courage and persistence to contribute to a better world based upon other than mainstream values [4].

Experiential Learning in Civic Contexts. Finally, experiential learning in civic contexts was added to the guidelines. Colby et al. [4] emphasize the value of student centered learning and of pedagogies that actively and emotionally involve students in the learning process. In addition, when students can practice in civic contexts what we hope that they will learn, these authentic and intrinsically interesting tasks can be provided. Experiential learning in civic contexts can provide these possibilities.
TABle 1: Curriculum guidelines Global Justice Citizenship Education.

\begin{tabular}{ll}
\hline Domains & Curriculum guidelines \\
\hline Knowledge domain & $\begin{array}{l}\text { (i) Gain historical (root causes of } \\
\text { injustice) insights and see } \\
\text { local-global connections } \\
\text { (ii) Focus on one global-justice issue }\end{array}$ \\
\hline & $\begin{array}{l}\text { (i) Develop ethical and intercultural } \\
\text { sensitivity } \\
\text { (ii) Recognize own values and } \\
\text { critically reflect on mainstream } \\
\text { thinking }\end{array}$ \\
\hline Soral domain & $\begin{array}{l}\text { (i) Contact people with different } \\
\text { socioeconomic positions, cultural } \\
\text { backgrounds and life chances } \\
\text { (ii) Get to know positive role } \\
\text { models: active and socially engaged } \\
\text { people }\end{array}$ \\
\hline Experiential learning & $\begin{array}{l}\text { (i) Spend at least 15 hours in civic } \\
\text { contexts [33] }\end{array}$ \\
\hline
\end{tabular}

Based upon Schutte [34].

The current case study investigated the effects of an undergraduate honors course called "Society 2.0" in the Netherlands, which is aimed at global citizenship. The Dutch educational context is characterized by socially segregated schools [23] and low scores on civic skills and attitudes towards foreigners $[24,25]$. Aims of citizenship education, such as active participation and social integration, relate to traditional national citizenship [26]. Furthermore, ethics are not explicitly treated. Under these circumstances, the youngsters' world could be broadened by contact with people from different socioeconomic and cultural backgrounds as well as by attention to their moral development.

Currently, honors programs are under development in Dutch higher education [27], which offers opportunities to develop new content and teaching methods, also on global citizenship.

In 2014, such an opportunity arose at the Hanze University of Applied Sciences, where two teachers, two students, and one researcher developed an undergraduate honors course "Society 2.0." The study load of the course is 112 hours, including eight class meetings of all together 16 hours (eight times two hours). The curriculum development team used the theory-based curriculum guidelines Global Justice Citizenship Education (see Table 1). The current study investigates the effects of the course as delivered in 2014 and 2015 on the participants of the two groups from both years.

Society 2.0 meets eight times for two hours (contact time), one evening every fortnight, and lasts four months. It focuses on alternative/social movements and their ideals (moral domain). The course starts with the values and norms of students' upbringing (moral domain) and then broadens out. Students delve into a societal theme (knowledge domain) and do a 15-hour internship at an alternative/social movement (experiential learning). While there, they interview people in that movement about their ideals (social domain, positive role models). In their lessons, the teachers cover different 
perspectives and the importance of being nonjudgmental (moral domain). They mostly function as coaches but also teach some theory about ethics, conformism, and cultures (moral domain). Students acquire knowledge on societal (global) issues by writing two blogs on a self-chosen theme, exploring its historical-future and local-global dimensions (knowledge domain). Furthermore, one meeting is dedicated to a global issue: "poverty" in the first course and the "free-trade treaty TTIP" in the second (knowledge domain). Students back up their opinions and provide references in their blogs. In the final meeting, students present a "oneminute paper" on how they will contribute to a better world. They also make a product in small groups demonstrating how others could learn from their exposure to global citizenship.

Society 2.0 ' is geared to honors students, that is, students who are both willing and able to go beyond the regular program in terms of academic challenge and personal development [28-30]. They do not comprise a homogeneous group $[31,32]$. Teaching honors students presumes that three conditions are met [28]: a safe learning community, academic challenge, and bounded freedom (facilitating autonomy and self-regulation). This pedagogical approach was applied to Society 2.0 .

The researcher attended the course meetings in 2014 and 2015 and made the following observations. A "typical lesson" would start with an inventory of students' experiences during the past two weeks, for instance, their (search for) internship or homework on ethics. Teachers ask who wants to share his/her experience, and individual students respond, after which other students and teachers ask questions and/or add their own experiences. Some lessons begin with a short film on an alternative movement, followed by questions: what did you see, what do you think, why did they start this, and which values are involved? The teachers provide an overview of each lesson and its aims and ask how students are getting on with their assignments. Sometimes students spontaneously tell about an experience connected to the course. Each lesson has a general part for the whole class and a breakout part in which students work in small groups of three or four. In lesson three, which focuses on ethics, the teachers first present theory and then the students share their own experiences of unethical behavior within the group. This is followed by a homework assignment in which students had to be alert to ethical conduct of themselves and others over the coming week and condense these observations into keywords. Several students present their experiences with that assignment at the beginning of lesson four. Teachers include multiple perspectives in every lesson. Each meeting ends by looking ahead to upcoming lessons and discussing the homework assignments.

Two cohorts of students (2014-2015; 2015-2016), altogether 25 students, participated in the study. The main question asked in the present study is what do students learn from the undergraduate honors course aimed at global citizenship? That question has been broken down into three subquestions: (SQ1) Do students show an increase in ethical sensitivity and global citizenship (social responsibility, global competence, and global civic engagement) after taking the course?; (SQ2) How do students express themselves regarding
TABLE 2: Characteristics of the participants.

\begin{tabular}{ll}
\hline Participants $(N=25)$ & Descriptive traits \\
\hline Age (mean) & 19-25 years (21.24) \\
\hline Female/male & Female 72\%/Male 28\% \\
\hline $\begin{array}{l}\text { Economy (10) } \\
\text { Law (5) } \\
\text { background students } \\
\text { (number) }\end{array}$ & $\begin{array}{l}\text { Sports (4) } \\
\text { Education \& } \\
\text { technical/computing (2) }\end{array}$ \\
\hline $\begin{array}{l}\text { Nursing \& communication (1) } \\
\text { (number) }\end{array}$ & $\begin{array}{l}\text { Second year (4); third year (16); } \\
\text { fourth year (5) }\end{array}$ \\
\hline $\begin{array}{l}\text { Educational } \\
\text { background } \\
\text { parents/caregivers }\end{array}$ & 56\% completed higher education \\
\hline $\begin{array}{l}\text { Perceived } \\
\text { cultural-ethnic } \\
\text { background (number) }\end{array}$ & Dutch (24); Dutch-Moroccan (1) \\
\hline
\end{tabular}

knowledge and ethics when writing about a societal issue?; and (SQ3) Which insights do participants of the course report regarding knowledge, ethics, and their role as global citizens when reflecting on the course?

\section{Methods}

2.1. Participants. The 25 students in this case study all participate in an honors talent program at their own institute/school, meaning that they follow a 30-ECTS two-year extracurricular program. ECTS refers to European Credit Transfer System. One point corresponds to 24 to 30 working hours for the average student. For an overview of the participants' characteristics, see Table 2. Regarding parental educational background, the percentage of having completed higher education is comparable with the overall student population of the Hanze University of Applied Sciences. It is above the average educational level in the Netherlands, as about $34 \%$ of the Dutch population completed higher education [35].

During the course, participants had to choose a societal topic. Twelve students $(46 \%)$ chose to write about a sustainability-related issue. Nine (35\%) chose an issue related to equality: either social/cultural, such as discrimination and social acceptance, or financial, such as equity-based crowd funding and unconditional basic income.

Participants further had to choose an organization to do a short internship. Fourteen students (54\%) chose an internship related to the issue they had written about. For instance S3, a business student, wrote blogs about self-sufficient living and did her internship at "Place the World," a place to work and share ideas on living with nature in a multicultural world. S14, studying human resource management, wrote blogs about discrimination and did her internship at the discrimination contact point. In other instances, the issue covered in the blog was not related to the internship: for example, S4, doing sports studies, wrote blogs about green playgrounds but did her internship at the discrimination 
contact point. S10, studying life science, wrote blogs about "art from waste" but did her internship at Young Gold, a project to promote volunteer work among youngsters. For three students the internship is unknown.

\subsection{Data Collection}

2.2.1. Instruments. For the quantitative measure to answer the first question, two instruments were used. The Ethical Sensitivity Scale Questionnaire (ESSQ) consists of seven dimensions and 28 items, which are measured on a 5point Likert scale $[36,37]$. There is some hierarchy in the dimensions, from basic to more complicated [38]. The operationalization of the Ethical Sensitivity model is satisfactory in that the psychometric properties of ESSQ are scientifically valid [36, 37, 39]. Reliability analysis of the subscales [40] yielded scores between $\alpha=.78$ and $\alpha=.50$. Reliabilities tend to be low due to the multidimensional construct as well as the high abstraction level of the concepts [36]. Two examples of the dimensions are "caring by connecting to others" (with the item "I tolerate different ethical views in my surroundings") and "working with interpersonal and group differences" (with the item "I try to consider another person's position when I face a conflict situation").

The Global Citizenship Scale (GCS) [41, 42] aims to measure global citizenship as an outcome of global education. GCS was used in this study because its three dimensions relate to the intended learning goals set forth in our curriculum guidelines GJCE. These dimensions are "social responsibility" (including social justice), "global competence" (including global knowledge and intercultural communication), and "global civic engagement" (including involvement in civic organizations and global civic activism). GCS was validated by means of two confirmatory factor analyses with multiple datasets [41], resulting in a measurement model of six first-order factors (self-awareness, intercultural communication, global knowledge, involvement in civic organizations, political voice, and global civic activism), three secondorder factors (social responsibility, global competence, and global civic engagement), and one higher-order factor (global citizenship). These results support its underlying theoretical model. Reliability analysis of the subscales [40] yielded scores from $\alpha=.69$ to $\alpha=.92$. The items of the GCS are measured on a 5-point Likert scale. For example, one item in the dimension "social responsibility" is "the world is generally a fair place." In the dimension "global competence", one item is "I am confident that I can thrive in any culture or country." Finally, in the dimension "global civic engagement", an item is "over the next 6 months, I plan to get involved in a program that addresses the global environmental crisis".

2.2.2. Data. To answer SQ1, a pre- and posttest design was used to measure the effect of the course on students' ethical sensitivity and global civic competence, engagement, and responsibility. Students filled out the questionnaires ESSQ $[36,37]$ and GCS $[41,42]$ in class at the beginning of the first course meeting (pretest) and at the end of the last course meeting (posttest). After being provided with an explanation about the research and the anonymously processing of the data, all the students agreed to participate.

To answer SQ2, how do students express themselves regarding knowledge and ethics when writing about a societal issue?, data were collected from two blogs that students had to write as part of their course assignments. For blog 2, they were asked to "explore a theme/issue that appeals to you and discuss a book, article, or presentation of your choice." For blog 3, they were asked to "locate your theme in a historic-future and local-global perspective." The collected data comprise 32,081 words $(N=24)$.

To answer SQ3, which insights do participants of the course report regarding knowledge, ethics, and their role as global citizens when reflecting on the course?, data were collected from their final blog on "reflection and evaluation" and from their answers to evaluation questions. These two questions are open-ended: (1) what is the most important thing that you learned about society? Please explain why this is important to you and (2) what possibilities do you see for yourself to contribute to a more just society in the future? The collected data comprise 12,595 words $(N=25)$. Again, the focus was on ethics and knowledge and on global citizenship: what do students write about their role as global citizens?

Finally, we investigated the students' perception on possible effects of the course half a year after they finished it. That time frame was selected because effects, especially in moral development, might fade away or appear after a course has ended [4]. Therefore all participants of the two courses were approached three times by email. In addition, participants of the second course were approached once through the Facebook group. In the end, data were collected from nine students. These nine were then invited for an interview, which started with the request to write (again) a blog giving their "reflection on the course" in about 15 minutes. After that, they were asked two questions: (1) what is the most important knowledge (emphasis) you gained from the course? and (2) what is the added value of the course in your daily life, how do you notice this, and how do other people notice this? Two of the interviews were conducted using Skype. The categories for each subquestion are shown in Table 3.

\subsection{Data Analysis}

2.3.1. Quantitative Analyses. The impact of the course on students' ethical sensitivity and global citizenship competence, social responsibility, and global civic engagement was tested by using the nonparametric Wilcoxon Signed Rank Test for repeated measures. A nonparametric test was chosen because of the small dataset in this study $(N=25)$.

2.3.2. Qualitative Analyses. First, two coders read and summarized all five blogs as to gain a gain a good understanding of the data. This wider frame helped to put outcomes of the actual analysis into perspective. After this, the blogs of interest for the current study (blogs 2, 3, and 5) were coded deductively using the following codebook. Regarding the category ethics, the code "ethical sensitivity", that is, writing about ethical aspects of a situation, was used. The 
TABLE 3: Data collection and qualitative data analysis subquestions 2 and 3.

\begin{tabular}{lcc}
\hline Subquestion & Data & Categories \\
\hline 2 & Blogs 2 and $3(N=24)$ & Knowledge and ethics \\
\hline 3 & Final blog + two open-ended evaluation questions $(N=25)$ & $\begin{array}{c}\text { Insights (knowledge, ethics, } \\
\text { global citizenship) and intentions } \\
\text { (role global citizen) }\end{array}$ \\
& Follow-up blog + interview $(n=9)$ & $\begin{array}{c}\text { Insights (knowledge, ethics) and } \\
\text { behavior (global citizen) }\end{array}$ \\
\hline
\end{tabular}

TABLE 4: Overview of codes for each category SQ2.

\begin{tabular}{ll}
\hline Category & Code \\
\hline Knowledge & $\begin{array}{l}\text { (i) Historical (-future) dimension } \\
\text { (ii) Local-global connection }\end{array}$ \\
\hline Ethics & $\begin{array}{l}\text { (i) Ethical sensitivity (both own behavior } \\
\text { and that of others/groups) }\end{array}$ \\
\hline
\end{tabular}

TABLE 5: Overview of codes for each category SQ3.

\begin{tabular}{ll}
\hline Category & Code \\
\hline $\begin{array}{l}\text { Intentions (future) } \\
\text { role as global citizen }\end{array}$ & (i) Sustainability-related \\
\hline & (ii) Social area \\
Insights & (i) Knowledge-related \\
& (ii) Ethics-related \\
& (iii) Global justice \\
citizenship (other)
\end{tabular}

dimensions from Narvaez's theory [38] on ethical sensitivity, which correspond with the ESSQ [36,37], were all categorized as "ethics." In addition to elements of caring ethics from this theory, also more "justice-oriented" fragments were coded "ethics." Furthermore, fragments were categorized under "ethics" not only when students wrote about their own attitude and behavior but also when they wrote about behavior and attitudes of others/groups in society. Regarding the category knowledge, the codes "historical dimension" and "local-global connections" were deduced from the curriculum guidelines GJCE. Furthermore, the code "global justice citizenship (other)" was used, which relates to the curriculum guideline "critically reflecting on (mainstream) values." Finally, regarding the impact of the course, the code "students" intentions regarding their role as global citizens' was added. Table 4 shows the categories and codes for SQ2 and Table 5 presents the categories and codes for SQ3.

Two coders independently coded all materials used in this qualitative part of our study. Coding was done by selecting the relevant parts of the blog-texts and by adding the code in the text margins. After the two different documents were combined into one and codes were compared as to establish interrater reliability, the coders discussed differences until agreement was reached. Then, in the next step, fragments falling within one category were put together. Finally representative examples were selected by the first and second author.

\section{Results}

3.1. Quantitative Results. A Wilcoxon Signed Rank Test revealed a statistically significant increase in ethical sensitivity after participating in Society 2.0 on three of the seven subscales. Regarding ESSQ 2: Taking the perspectives of others, $z=-2.131, p<.033$ with a medium effect size $(r=.30)$ using Cohen [43] criteria of $.1=$ small effect, .3 $=$ medium effect, and $.5=$ large effect. The median score on "taking perspectives of others" increased from $(\mathrm{Md}=3.88)$ before the course to $(\mathrm{Md}=4.25)$ after the course. Regarding ESSQ 3: Caring by connecting to others, $z=-2.179, p<.029$ with a medium effect size $(r=.31)$. The median scores on "caring by connecting to others" were the same on both occasions $(\mathrm{Md}=4.00)$. And regarding ESSQ 5: Preventing social bias, $z=-2.695, p<.007$ with a medium effect size $(r=.38)$. The median score on "preventing social bias" increased from $(\mathrm{Md}=3.50)$ to $(\mathrm{Md}=3.75)$ after taking the course. See Table 6 for details on these results.

Regarding global citizenship as measured by the GCS, a Wilcoxon Signed Rank Test revealed a significant increase across all three subdimensions of global civic engagement and in two of the three subdimensions of global competence, namely, self-awareness and global knowledge. The results are as follows. Self-awareness: $z=-4.00, p<.0005$ with a large effect size $(r=.57)$. The median score on "self-awareness" increased from $(\mathrm{Md}=2.67)$ at the outset to $(\mathrm{Md}=3.67)$ after taking the course. Global knowledge: $z=-3.02, p<.003$ with a medium to large effect size $(r=.43)$. The median score on "global knowledge" increased from $(\mathrm{Md}=3.33)$ to $(\mathrm{Md}=$ 3.67). Involvement in civic organizations: $z=-2.79, p<.005$ with a medium to large effect size $(r=.40)$. The median score on "involvement in civic organizations" increased from $(M d$ $=2.75)$ to $(\mathrm{Md}=3.25)$. Political voice: $z=-2.53, p<.011$ with a medium size $(r=.36)$. The median score on "political voice" increased from $(\mathrm{Md}=2.25)$ to $(\mathrm{Md}=2.75)$. Global civic activism: $z=-2.93, p<.003$ with a medium to large effect size $(r=.40)$. The median score on "global civic activism" increased from $(\mathrm{Md}=3.00)$ to $(\mathrm{Md}=3.33)$ after taking the course. See Table 7 for further details.

To summarize the results from the quantitative part of our research on the effect of participation in Society 2.0, it was found that students showed an increased score on three of the seven dimensions of ethical sensitivity (with medium effect sizes). Further, students' scores had also increased on two of the three dimensions and within those on five of the six subdimensions of global citizenship (with medium to high effect sizes). 
TABLE 6: Pre- and posttest differences on ethical sensitivity (ESSQ). $N=25$.

\begin{tabular}{|c|c|c|c|c|}
\hline ESSQ & Md (pre) & Md (post) & $Z(p)$ & $r$ \\
\hline (1) Reading and expressing emotions & 4.00 & 4.00 & $-.84(.400)$ & .12 \\
\hline (2) Taking the perspectives of others & 3.88 & 4.25 & $-2.13(.033)$ & .30 \\
\hline (3) Caring by connecting to others & 4.00 & 4.00 & $-2.18(.029)$ & .31 \\
\hline (4) Working with interpersonal and group differences & 3.75 & 3.75 & $-1.77(.077)$ & .25 \\
\hline (5) Preventing social bias & 3.50 & 3.75 & $-2.695(.007)$ & .38 \\
\hline (6) Generating interpretations and options & 3.67 & 4.00 & $-1.61(.107)$ & .23 \\
\hline (7) Identifying the consequences of actions and options & 3.50 & 3.75 & $-1.88(.060)$ & .27 \\
\hline
\end{tabular}

Table 7: Pre- and posttest differences on the Global Citizenship Scale (GCS), $N=25$.

\begin{tabular}{|c|c|c|c|c|c|}
\hline Dimension & Subdimension & (Md) pre & $(\mathrm{Md})$ post & $Z(p)$ & $r$ \\
\hline Social responsibility & & 4.00 & 4.00 & $-.23(.818)$ & .03 \\
\hline \multirow{3}{*}{ Global competence } & Self-awareness & 2.67 & 3.67 & $-4.00(.000)$ & .57 \\
\hline & Intercultural communication & 4.00 & 3.67 & $-.36(.720)$ & .05 \\
\hline & Global knowledge & 3.33 & 3.67 & $-3.02(.003)$ & .43 \\
\hline \multirow{3}{*}{ Global civic engagement } & Involvement in civic organizations & 2.75 & 3.25 & $-2.79(.005)$ & .40 \\
\hline & Political voice & 2.25 & 2.75 & $-2.53(.011)$ & .36 \\
\hline & Global civic activism & 3.00 & 3.33 & $-2.93(.003)$ & .40 \\
\hline
\end{tabular}

3.2. Qualitative Results. SQ2: How do students express themselves regarding knowledge and ethics when writing about a societal issue? Content analysis of the blogs that students wrote about a self-chosen societal issue revealed the following points. Sixteen students (67\%) wrote about knowledge in the way we defined it (historical-future and local-global connection). Fourteen out of 24 (58\%) treated the historical dimension in one way or another, mostly in a few (four to nine) sentences. Five students described the historical dimension from the angle of an alternative movement rather than of a societal/global issue. For instance: (S15) The strange thing about self-sufficient living is that it is not a new lifestyle at all, because in earlier days we all had to organize and arrange our own food and ways to keep warm. [...] nowadays we forget how it will be to take care of your own food and heating. A second example is the following: (S8) Permaculture was invented in 1970 by two Australians, Bill Mollison and David Holmgren from the university of Tasmania. Together they did research on the functioning of the ecosystem in the Tasmanian forests. The research was motivated by agricultural issues that were going on. The aim was to formulate principles to enable man to build and maintain an ecosystem with optimal attention for nature.

An example touching upon the historical dimension of discrimination is the following blog. (S14) drew connections with what she learned at her previous school about not being allowed to discriminate. The examples she used were World War II, racial segregation in the USA, and "apartheid" in South Africa. She tried to find out if it is possible to see a turning point in the way people (in a certain country) think about discrimination. She wrote that she came to realize the answer to this question can be different depending on the country and the ethnic group involved.
Regarding the local-global perspective, it was found that 11 students $(46 \%)$ dealt with that topic in one way or another. Two of them wrote about an issue that is often not perceived to play a role in the Netherlands, just in other parts of the world. (S25) wrote about poaching: I always thought that animals living in the nature in the Netherlands had a rather good life here, but that is not true at all: 3663 poaching alerts within one year. The other student (S20) argued that the impact of internet censorship is not as dependent on location as people seem to think and not limited to countries like China and North Korea. In the Netherlands there is trust in the government and the legislation. However, from the examples [this student gave] it is clear that in democratic politics also a lot of "people-unfriendly" decisions are being made.

Other students also wrote on this aspect. For instance, one (S7) described the international framework of human rights, such as the universal declaration of human rights and the EU legislation. Another (S18) mentioned the global scope of the effects of the use and depletion of fossil fuels. Yet another (S2) compared the attitude of Dutch people on homosexuality with that of people in several other countries.

When coding the blogs, we noticed that students had learned both from reading each other's blogs and in interaction with each other. Students responded to each other's blogs, writing that an issue was new for them and that they were interested in it. Furthermore, they asked followup questions. For instance (S13): Nice blog! I also think it is a very interesting issue (barter economy). Are you familiar with the trend that people even exchange food that they have left over; such follow-up was often about the other student's experiences and opinions. Several also delivered new input on the issue. For instance, Your blog reminded me of my own "doubts" about what to do in life to and how to become more 
TABLE 8: Overview of codes assigned for each category SQ2, $N=24$.

\begin{tabular}{llcc}
\hline Category & Code & Number of students & Number of fragments \\
\hline \multirow{2}{*}{ Knowledge/insights } & (i) Historical (future) dimension & 14 & 22 \\
& (ii) Local-global connection & 11 & 11 \\
\hline Ethics & (i) Ethical sensitivity (both own behavior and that of others/groups) & 14 & 30 \\
\hline
\end{tabular}

happy. [...] I also immediately thought of a book I am reading [...]. For an overview of the assigned codes for knowledge and ethics, see Table 8.

Fourteen students (58\%) described ethical aspects and/or ethical considerations, either in their own blogs or in response to those of others. In total 30 separate fragments were coded "ethical sensitivity." Most writings concern ethical aspects of the theme/social issue students had written about. Four students wrote about unethical behavior in society in the form of discrimination. One (S14) provided a detailed analysis of the process of discrimination. After that she showed sensitivity to social bias, writing When being white in the Netherlands wanting to avoid racism, one easily makes the mistake to become defensive and forget that you were influenced by the system you grew up in. The writers go on to relate this knowledge to his/her own thoughts and behaviors. Another student (S26) also noticed the prevalence of discrimination and subsequently wrote, Fighting discrimination starts with yourself.

Four more students focused on social inequality and ways to overcome it. For instance, regarding unconditional basic income (S5), A man had to apply for jobs because he was obliged to find a job as soon as possible, whilst being out of work meant he could take care of his ill mother, who otherwise would have to go to a nursing home. Another student (S13) showed involvement with the welfare of others by writing I believe this initiative [store for homeless people] is great. Homeless people getting the opportunity to pick out free clothing.

Two other students wrote about the unethical behavior of states and banks. One (S20) described how unlawful behavior of intelligence agencies has consequences for people's privacy. In a similar vein, (S19) detected a risk for low-educated people to become victims of nearly bankrupt enterprises. In response to that blog, another student (S12) proposed possible solutions to this problem, namely, establishing a "watchdog" and providing information.

Finally four students wrote about ethical aspects of sustainable food issues. As one wrote With the same reasons (money, lust) people kill animals. Why they do it, I can't understand.

Although the fragments on ethics were not coded separately on the different dimensions of ethical sensitivity, we noticed that the fragments mainly reflect the following dimensions: involvement with welfare of others (ES3); seeing own prejudices, social bias regarding ethical issues (ES5); looking for alternative solutions for ethical problems (ES6); and seeing consequences of actions and options (ES7).

SQ3: Which learning outcomes do participants of the course report regarding global citizenship, ethics, and knowledge when reflecting on the course? When writing about intentions regarding their role as global citizen, sustainability came up 12 times (48\%). Seven students did formulate intentions regarding their own sustainable behavior: eat no meat or less meat; use less packaging; reuse things; buy secondhand clothes; exchange and share; make use of local gardens; eat vegetables in season and biological food; and do not unnecessarily turn on the lights. Three students formulated other intentions regarding sustainability. For instance, (S4) wrote Now that the course has ended I want to further delve into this subject (green playgrounds) and hope to start this project in several towns. (S3) wrote, I intend to help spread the message about sustainable living for man, plants and animals. And (S15) wrote Finally I found something concrete in my own discipline (civil engineering): building with nature. One student (S15) wrote The most valuable [lesson] I learned from my internship (and the course) is the knowing that you are not alone. You never are the only one who worries (in my case about the climate) about the world. Speak out your "worries" and especially what you are interested in. When people hear that you are interested in something, they might (unconsciously) look for information and soon something might come up for you.

Twelve students (48\%) formulated intentions in the social area. Four of them intend to do or continue volunteer work (S6, S10, S15, and S20). For instance (S15) wrote One year ago I stopped with volunteer work, which I did since I was 16 years old. During the course I noticed how much I miss that, so I will immediately look for that again. Another student was looking specifically into how he can contribute to the town he is living in (S8). Two more students had already started with volunteer work (S26, S18). The intentions of the last four were related to equality, justice, and ethics. (S16) wrote Bring several cultures together by means of organizing a festival on short notice focusing on the multicultural society. The idea is that bands from [town] and from the asylum seekers center perform together, and the aim to connect people [this has been accomplished during the course]. (S9): I study law and that is where I see myself contribute to a more just society in the future. (S22): Inform and activate other people and make them aware of ethical issues. Finally, two students emphasized the importance of taking small steps at a time. For instance (S14) wrote I came to realize that I have to focus on specific issues and take one step at a time.

Regarding insights gained from the course, 19 students (76\%) mentioned ethical aspects in altogether 38 fragments. Fourteen students mentioned that they are more aware of or have more respect for people who are different from themselves. Their comments reflect two dimensions of ethical sensitivity: exploring multiple perspectives (ES2) and understanding that differences could lead to misunderstandings (ES4). For instance (S22) wrote Respect each other's identity, try not to judge and pay respect. And (S25) wrote last year 
TABLE 9: Overview of codes assigned for each category SQ3, $N=25$.

\begin{tabular}{llcc}
\hline Category & Code & Number of students & Number of fragments \\
\hline \multirow{3}{*}{ Intentions (future) role as global citizen } & (i) Sustainability-related & 12 & 16 \\
& (ii) Social area & 12 & 13 \\
& (iii) Other & 4 & 4 \\
\hline \multirow{3}{*}{ Insights } & (i) Knowledge-related & 18 & 27 \\
& (ii) Ethics-related & 19 & 38 \\
& (iii) Global justice citizenship (other) & 5 & 5 \\
\hline
\end{tabular}

was a period in which my world became much broader and I developed more respect for "things" which are different. (S4) wrote After my internship I came to realize that I also have prejudices about other people and other cultures. (S5) wrote [...] We talked a lot about homeless people and also about people who live in poverty, and who, according to us, sometimes make stupid choices (you don't smoke if you do not have money, do you). We can in no way judge about this, without knowing more about people, situations and surroundings. So sometimes it is good to not take your own view and prejudices too seriously and important to be a little more forward looking. And (S16): [...] I was opposed to refugees, but thanks to the course and especially insights from others, my thoughts about this have been changed.

Two students wrote that all alternative movements deserve respect. Also two students mentioned that they have become more aware of ethics, norms, and values. For instance (S23): I more often remark on ethical aspects and talk with others about that. I also notice that I more often watch interesting documentaries about this subject. One student (S25) wrote that the most important lesson she learned about society concerned The helping of each other. People are there for you and that is a reassuring feeling. Also one student wrote that he is more aware of other people (S8): I cycle through the city more happily and notice more the people around me. I more often talk with them and in that way come to know things. This interest for people from Groningen has been aroused by the course "Society 2.0." Finally, one student (S9) wrote Society only functions if we keep talking to each other. Ignorance creates a distinction between groups within society.

Eighteen students (72\%) reported knowledge-related insights in altogether 27 text fragments. Almost all of these refer to gaining broader knowledge and a broader view. For instance (S13) wrote I became fascinated by the barter economy. (S17): An inspiring group of motivated students have also pointed out all kinds of movements to make this world an even better place. (S23): I learned a lot about society, about different cultures, alternative movements and ethical aspects. Very important aspects which are not always being discussed in daily life. (S24): I am much more aware of what is going on in the world and I notice more articles about a societal theme like TTIP, which I then read with pleasure.

Other insights, specifically regarding global justice citizenship, were reported by five students (20\%). Two students wrote about equality. For instance (S10) wrote I learned it is good to help a little in society, but that help is not always necessary whilst "we people from western countries" feel the urge to help people living in a less prosperous countries then we do "the white savior syndrome". Two students wrote about the importance of collective action/cooperation for a better world. For instance (S6) wrote When I look at the Netherlands I can see that we have become more individualistic. We have to collaborate to make the world a better place. We expect too soon that other people will change and that it is no use to do something on your own. Although you will have to collaborate, you can also contribute on your own. As one student (S19) remarked when asked to describe the most important lesson (s)he had learned from Society 2.0, it was that most people think too mainstream. For an overview of assigned codes regarding students' intentions as global citizen and gained insights, see Table 9.

When coding the students' final blogs, we also noticed that students often said they learned from their internship. Seventeen of the 25 students mentioned the internship in altogether 45 fragments.

With regard to the students' perception on effects on them $(n=9)$ half a year after the course was finished, the following points were found. Students wrote in their follow-up blogs about how the course still influenced them. Three of them mentioned paying more attention to their surroundings. For instance (S1) mentioned seeing more what happens around me; and (S3) recalled noticing more small initiatives when walking in the street. Others reported that they developed a different view or perspective. (S17): developed critical look regarding certain issues, for instance TTIP. (S19) reported notice that I look from a different perspective, which sometimes leads to nice insights in the tough financial world. And related to ethics, (S1) is looking for alternative solutions for problems, also involving fairness.

When asked about specific knowledge gained from the course, all but one student said things like "not particularly knowledge." (S8): thoughts and ideas that you share with others and that help broaden your horizon. (S3): that you have to start with yourself, but after that it is also important to share your ideas or initiatives. (S1): alternative movements, what you can reach with those, however small they may be. And (S14): I better think about my own opinion, have become more critical. One student did mention gaining specific knowledge, but not on a global issue. (S7): what I really remember is conformism, I knew the concept but never gave it much thought. How she [the teacher] told about it, I thought yes, everybody does it, it just happens.

When asked for the added value in their daily lives, three students mentioned the dialogue with others, for instance 
(S8): I share more thoughts and ideas with people and take initiatives to do things together (with colleagues). (S14): [...] more open to opinions of others and take things not personally anymore. Another student brought up the attitude towards others (S7): Try to be positive and gay every day and give compliments and also become happy from the reactions I get.

Two more students mentioned ethics-related aspects. (S1): pay more attention to someone else's norms and values. (S5): my acting has changed a lot, for instance regarding homeless people, "you have a lot less than I have while I can easily do with a little less money".

Four students mentioned sustainable behavior: (S5): change of lifestyle, more fresh and biological food; (S1): more thrifty with waste; (S17): eat less meat and more aware of power consumption; and (S7): don't let the water run, removing the electric plug, don't leave the lights on and so on. One student mentioned now being able to acquire deeper knowledge (S5): more deepening when reading a magazine on global justice issues.

\section{Discussion and Limitations}

In our research on the effects of a global citizenship course on the participants, quantitative results showed a positive impact on students' ethical sensitivity as well as on their attitude and behavior as global citizen. The analysis of both students' work and their perception on what they learned points in the same direction. The course offered them new insights and broader knowledge, made them think about ethical issues and their values, and stimulated them to deal with their role as global citizen.

To answer the first subquestion SQ1: do students show an increase in ethical sensitivity and global citizenship (social responsibility, global competence, and global civic engagement) after taking the course?, a quantitative measure of ethical sensitivity ESSQ and the global citizenship GCS in a pre- and posttest design were used. Results revealed increased ethical sensitivity on three of the seven dimensions of the ESSQ: "taking the perspective of others" (which relates to exploring multiple perspectives on situations and events); "caring by connecting to others" (which relates to the process of expanding one's sense of self to include others and involves developing a sense of connectedness to other people, both globally and locally); and "preventing social bias" (which involves understanding, identifying, and actively countering bias). Effect sizes were medium. No significant increase in scores was found on four dimensions: "reading and expressing emotions," "working with interpersonal and group differences," "generating interpretations and options," and "identifying the consequences of options and actions."

Results regarding global citizenship revealed an increased score on the dimensions "global civic engagement" and "global competence." Effect sizes were medium to high. Global civic engagement relates to involvement in civic organizations, political voice, and global civic activism. Regarding global competence, an increased score was found on "self-awareness" (recognizing own limitations and ability to engage successfully in an intercultural encounter) and "global knowledge" (displaying interest and knowledge about world issues and events) but not on intercultural communication. Students' scores did not significantly increase on the third dimension, namely "social responsibility" (awareness of interdependence and social concern for the environment, other people, and society in general). This result might be related to the rather high score on both intercultural communication and social responsibility that the students already had recorded at the start of the course $(\mathrm{Md}=4$ on a 5-point Likert scale).

Based on these results it can be concluded that students increased their ethical sensitivity as well as their global competence and global civic engagement by taking the course. However, the absence of a control group means that the results should be interpreted with some caution, as it cannot be proven that it was solely the course that caused this increase. Furthermore, the sample size of 25 students is rather small and should be considered a major limitation with regard to the quantitative analyses with the instruments ESSQ and GCS.

Regarding our second subquestion (SQ2), how do students express themselves in the knowledge and ethics when writing about a societal issue?, content analyses of two blogs revealed that students dealt in some way with ethical aspects and knowledge when writing about a self-chosen societal issue. For instance, they wrote about the ethical aspects of discrimination, unconditional basic income, behavior of states and banks, and sustainability. With regard to knowledge most of the writings about historical aspects were found to be short. Notably, the students had learned about each other's issue and in that way broadened their knowledge about societal/global issues. Students regularly expressed enthusiasm about new insights, although it cannot be proven that what they wrote in their blogs is a reflection of new knowledge acquired in the course.

Regarding our third subquestion (SQ3), which insights do participants of the course report regarding ethics, knowledge and their (future) role as global citizen when reflecting on the course?, students reported knowledge-related insights, mostly referring to broader knowledge and a broader view. Likewise, students reported ethics-related insights, especially having more respect for people different from themselves. Signs of insight into other aspects of justice-oriented global citizenship were also visible, namely, regarding equality, individualism, and mainstream thinking. It was further noted that students wrote about the importance of their internship. Students' intentions about their (future) role as global citizen were equally related to sustainability and to the social arena, such as volunteering, bringing cultures together or striving for more justice within their profession. Although the giving of politically correct answers cannot entirely be excluded, we think that there are several circumstances in this course that might make the probability of this kind of answering smaller. First: in this course there is not something like right or wrong according students' intentions for the future. Instead students reflected on their intentions and plans during the course and had to give arguments for choices. Second: in that same vein, there were students who did not have concrete plans yet, but nevertheless passed the course. Third: several of the intentions of students were already put to practice and 
students wrote and told about what they learned from it; hence this did reflect their behavior and not a tendency to come across as, for example, ethical. Fourth: in their blogs and during classes (observed by the first author), students showed severe enthusiasm about new insights and new experiences they got and intentions were linked to these insights and experiences, for instance, becoming vegetarian, organizing a cultural festival with refugees and inhabitants of a village, and making more active contact with unknown others.

Finally, from the follow-up blog and interview among nine students half a year after participating in the course, it can be concluded that students experienced that Society 2.0 still had an influence on them. This was especially apparent in their writing and talking about taking a different perspective and paying more attention to (people in) their surroundings. Students mentioned that they gained more insights than specific knowledge, giving the importance of sharing ideas as an example. Regarding behavior, five students mentioned that their attitude towards others had changed (towards sharing ideas, paying more attention) and four students remarked that they were behaving more sustainably.

It should be noted that not all students were interviewed; only nine participated in the follow-up blog and interview. It might be that the students who agreed to participate in an evaluation six months after taking the course are not representative for the whole group. However, the fact that no more students signed up for the follow-up study, even though their involvement with the course seemed to be deep, could be related to the extra workload of 15 ECTS each year in an honors program and to the half-year internship in the third year of study, conditions that applied to $64 \%$ of the students in this course.

The reason why this course had a positive impact on the participating students could be related to the use of the theory-based insights underlying the development of the course as well as to the teaching behavior. Regarding the theory, the curriculum guidelines GJCE in the knowledge, moral and social domains combined with experiential learning, were largely implemented in the course. Several ways of gaining more knowledge on societal/global issues were combined with explicit attention for ethics and an internship at an alternative social movement. The latter activity offered new perspectives on mainstream values and positive role models for the students.

Theoretical insights regarding honors pedagogies were also implemented and might have contributed to the results of the course as well. These were offering a safe learning community, academic challenge, and bounded freedom [28]. Of special note is that a great deal of freedom was offered. Students could choose an issue to write about, an internship, and the form and content of their final assignment. Community-building was accomplished in two ways: the course was started with attention for the values and norms the students were brought up with; and the teachers offered space for the students to exchange experiences related to the course. Students wrote they had learned from each other. Teachers also paid attention to different perspectives and emphasized being nonjudgmental, which is reflected in the students' writing and perceptions of what they learned.
Despite the positive outcomes of the course, students seem to have merely broadened their knowledge and hardly gained insight into the root causes of injustice, which is one of the curriculum guidelines GJCE. To achieve the latter aim, a more extended course will probably be necessary. Moreover, specific attention would have to be given to the structures that maintain injustice for the students to develop such insights.

Also, it should be kept in mind that the participants in this case study were honors students. The results might be different for regular (i.e., nonhonors) students. One reason for this is that high ability students on average reveal more interest in ethical issues [36, 44]. Finally, students deliberately chose to participate in this course aimed at global citizenship. Making that choice implies that they were already motivated to find answers about their role as citizen or were at least curious about the subject of global citizenship. The results might be different when such a course is mandatory. However, three principles that teachers applied in the course "Society 2.0" could also contribute to positive results in other contexts: starting with the student (in this case relating their background to their values and opinions); responding to differences between students; and making of adaptions in the course program when it seems necessary for the students' learning.

\section{Conclusions}

Under current conditions of emerging populism and severe ecological problems worldwide, undergraduate students should be able to count on our help and support in their efforts to gain deeper insights in the global society and to find their own way to act as an engaged global citizen. Honors students especially, with their above-average motivation, abilities, and interest in moral issues, could also contribute to solutions of global justice and sustainability issues. The results of our case study show that a 112-hour theory-based global citizenship course can have a positive impact on undergraduate honors students' insights, ethical sensitivity, and the development of attitudes and behaviors as engaged citizens.

\section{Conflicts of Interest}

The authors declare that there are no conflicts of interest regarding the publication of this paper.

\section{Acknowledgments}

The authors like to thank the Hanze Honours College, Loes Damhof, Anique Elling, Nelleke de Jong, Arie Kool, Jacqueline Selker, and Richard Wiltjer for their positive and indispensable contribution to this study.

\section{References}

[1] K. L. Gibson, G. M. Rimmington, and M. Landwehr-Brown, "Developing global awareness and responsible world citizenship with global learning," Roeper Review, vol. 30, no. 1, pp. 1123, 2008. 
[2] S. Lee, P. Olszewski-Kubilius, R. Donahue, and K. Weimholt, "The Civic leadership institute: a service-learning program for academically gifted youth," Journal of Advanced Academics, vol. 19, no. 2, pp. 272-308, 2008.

[3] D. V. Lovecky, "Moral sensitivity in young gifted children," in Morality, Ethics, and Gifted Minds, D. Ambrose and T. Cross, Eds., pp. 161-176, Springer, Dordrecht, The Netherlands, 2009.

[4] A. Colby, T. Ehrlich, E. Beaumont, and J. Stephens, Educating Citizens. Preparing America's Undergraduates for Lives of Moral and Civic Responsibility, Jossey-Bass, San Francisco, Calif, USA, 2003.

[5] K. L. Gibson and M. Landwehr-Brown, "Moral development in preparing gifted students for global citizenship," in Morality, Ethics, and Gifted Minds, D. Ambrose and T. Cross, Eds., pp. 301-312, Springer, New York, NY, USA, 2009.

[6] L. Johnson and P. Morris, "Towards a framework for critical citizenship education," Curriculum Journal, vol. 21, no. 1, pp. 7796, 2010.

[7] J. Westheimer and J. Kahne, "What kind of citizen? The politics of educating for democracy," American Educational Research Journal, vol. 41, no. 2, pp. 237-269, 2004.

[8] M. C. Nussbaum, Cultivating Humanity, Harvard University Press, Cambridge, UK, 1997.

[9] M. Nussbaum, "Education for citizenship in an era of global connection," Studies in Philosophy and Education, vol. 21, no. 45, pp. 289-303, 2002.

[10] K. Tirri, "Holistic school pedagogy and values: Finnish teachers' and students' perspectives," International Journal of Educational Research, vol. 50, no. 3, pp. 159-165, 2011.

[11] K. Tirri and E. Kuusisto, "How Finland serves gifted and talented pupils," Journal for the Education of the Gifted, vol. 36, no. 1, pp. 84-96, 2013.

[12] S. Tolppanen and K. Tirri, "How an enrichment summer program is meeting the expectations of gifted science students: a case study from Finland," International Journal for Talent Development and Creativity, vol. 2, no. 1, pp. 103-117, 2014.

[13] V. Andreotti, "Soft versus critical global citizenship education," Development Education, Policy and Practice, vol. 3, no. 1, 2006.

[14] I. Davies, M. Evans, and A. Reid, "Globalising citizenship education? A critique of 'global education' and 'citizenship education," British Journal of Educational Studies, vol. 53, no. 1, pp. 66-89, 2005.

[15] Oxfam GB, "Education for Global Citizenship: a guide for schools," 2006, http://www.oxfam.org.uk/education/global-citizenship/global-citizenship-guides.

[16] K. Holm, P. Nokelainen, and K. Tirri, "Relationship of gender and academic achievement to finnish students' intercultural sensitivity," High Ability Studies, vol. 20, no. 2, pp. 187-200, 2009.

[17] M. R. Hammer, M. J. Bennett, and R. Wiseman, “The intercultural development inventory: a measure of intercultural sensitivity," International Journal of Intercultural Relations, vol. 27, pp. 421-443, 2003.

[18] K. Holm, Ethical, Intercultural and Interreligious Sensitivities. A Case Study of Finnish Urban Secondary School Students, Waxmann, Münster, Germany, 2012, Ethical, Intercultural and Interreligious Sensitivities. A case study of Finnish urban secondary school students.

[19] M. J. Bebeau, J. R. Rest, and D. Narvaez, "Beyond the promise: a perspective on research in moral education," Educational Researcher, vol. 28, no. 4, pp. 18-26, 1999.
[20] M. Friedman, “Educating for world citizenship," Ethics, vol. 110, no. 3, pp. 586-601, 2000.

[21] B. W. Kliewer, "Why the Civic engagement movement cannot achieve democratic and justice aims," Michigan Journal of Community Service Learning, vol. 19, no. 2, pp. 72-79, 2013.

[22] G. Garland Reed, "The complexity of moral learning: diversity, deprovincialisation and privilege," Journal of Moral Education, vol. 40, no. 3, pp. 359-367, 2011.

[23] W. H. Schmidt, N. A. Burroughs, P. Zoido, and R. T. Houang, "The role of schooling in perpetuating educational inequality: an international perspective," Educational Researcher, vol. 44, no. 7, pp. 371-386, 2015.

[24] W. Schulz, J. Ainley, J. Fraillon, D. Kerr, B. Losito, and ICCS., ICCS 2009 International Report: Civic Knowledge, Attitudes, and Engagement among Lower-Secondary School Students in 38 Countries, IAE, Amsterdam, The Netherlands, 2010.

[25] W. Veugelers, "Theory and practice of citizenship education. The case of policy, science and education in the Netherlands," Journal of Education, pp. 209-224, 2011.

[26] W. Veugelers, "A humanist perspective on moral development and citizenship education," in Education and Humanism, W. Veugelers, Ed., pp. 9-34, Sense Publishers, Rotterdam, the Netherlands, 2011.

[27] M. V. C. Wolfensberger, Talent Development in European Higher Education: Honors Programs in the Benelux, Nordic and German-Speaking Countries, Springer, Cham, Switzerland, 2015.

[28] M. V. C. Wolfensberger, Teaching for Excellence: Honors Pedagogies Revealed, Waxmann, Münster, Germany, 2012.

[29] L. Clark and J. Zubizaretta, Eds., Inspiring Exemplary Teaching and Learning Perspectives on Teaching Academically Talented College Students, NCHC, Lincoln, Neb, USA.

[30] T. P. Hébert and M. T. McBee, "The impact of an undergraduate honors program on gifted university students," Gifted Child Quarterly, vol. 51, no. 2, pp. 136-151, 2007.

[31] C. Achterberg, "What is an honors student?" Journal of the National Collegiate Honors Council, vol. 6, no. 1, pp. 75-83, 2005.

[32] A. N. Rinn and J. A. Plucker, "We recruit them, but then what? The educational and psychological experiences of academically talented undergraduates," Gifted Child Quarterly, vol. 48, no. 1, pp. 54-67, 2004.

[33] K. J. Strand, S. Marullo, N. Cutforth, R. Stoecker, and P. Donohue, Community-Based Research and Higher Education: Principles and Practices, John Wiley \& Sons, San Francisco, Calif, USA, 2003.

[34] I. W. Schutte, "Honours and global citizenship education," in Proceedings of the Symposium held during the annual Educational Research Days, A. Timmermans, Ed., Maastricht, the Netherlands, June 2011, https://hbo-kennisbank.nl/nl/page/ search.

[35] CBS, Centraal Bureau voor de Statistiek (CBS), Dienst Uitvoering Onderwijs (DUO) en het Ministerie van Onderwijs, Cultuur en Wetenschap (OCW), Kengetallen, 2013, http://www.onderwijsincijfers.nl/.

[36] K. Tirri and P. Nokelainen, "Comparison of academically average and gifted students' self-rated ethical sensitivity," Educational Research and Evaluation, vol. 13, no. 6, pp. 587-601, 2007.

[37] K. Tirri and P. Nokelainen, Identifying and Measuring Multiple Intelligences and Moral Sensitivities in Education, Sense Publishers, Rotterdam, The Netherlands, 2011.

[38] D. Narvaez, Ethical Sensitivity: Nurturing Character in the Classroom, EthEx Series Book 1, 2001. 
[39] K. Gholami and K. Tirri, "The cultural dependence of the ethical sensitivity scale questionnaire: the case of iranian Kurdish teachers," Education Research International, vol. 2012, Article ID 387027, pp. 1-9, 2012.

[40] L. J. Cronbach, Essentials of Psychological Testing, Harper \& Row, New Jersey, NJ, USA, 4th edition, 1984.

[41] D. B. Morais and A. C. Ogden, "Initial development and validation of the global citizenship scale," Journal of Studies in International Education, vol. 15, no. 5, pp. 445-466, 2011.

[42] J. S. Lang, Assessing the impact of various experiences on students' levels of global citizenship [M.S. thesis], Oregon State University, Corvallis, Ore, USA, 2013.

[43] J. W. Cohen, Statistical Power Analysis for The Behavioral Sciences, Laurence Erlbaum Associates, Hillsdale, NJ, USA, 2nd edition, 1988.

[44] I. W. Schutte, M. V. C. Wolfensberger, and K. Tirri, "The relationship between ethical sensitivity, high ability and gender in higher education students," Gifted and Talented International, vol. 29, no. 1-2, pp. 39-49, 2014. 


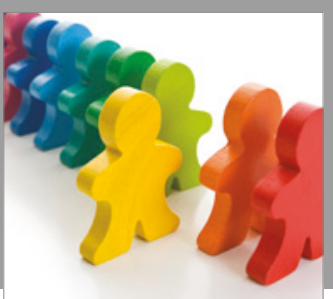

Autism

Research and Treatment
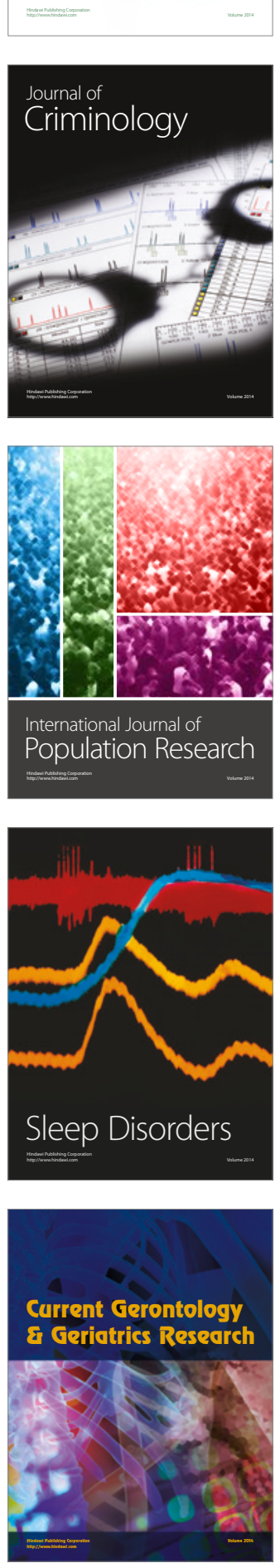

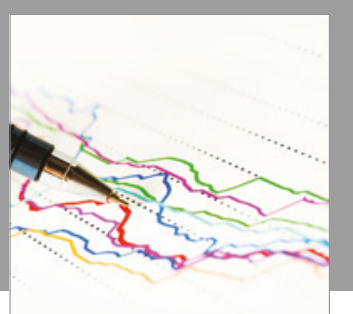

Economics

Research International

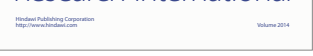

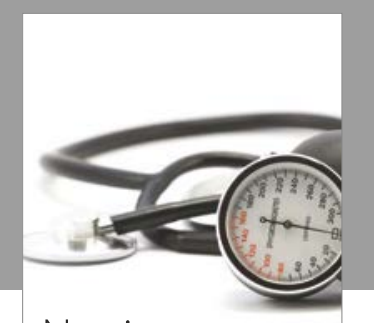

Nursing

Research and Practice

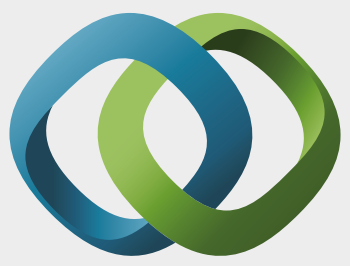

\section{Hindawi}

Submit your manuscripts at

https://www.hindawi.com
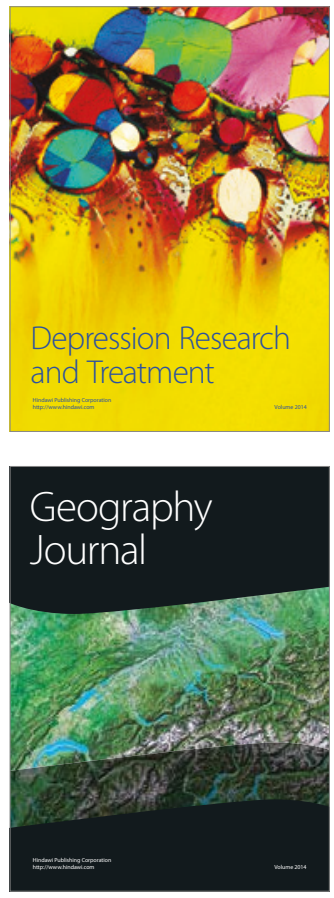
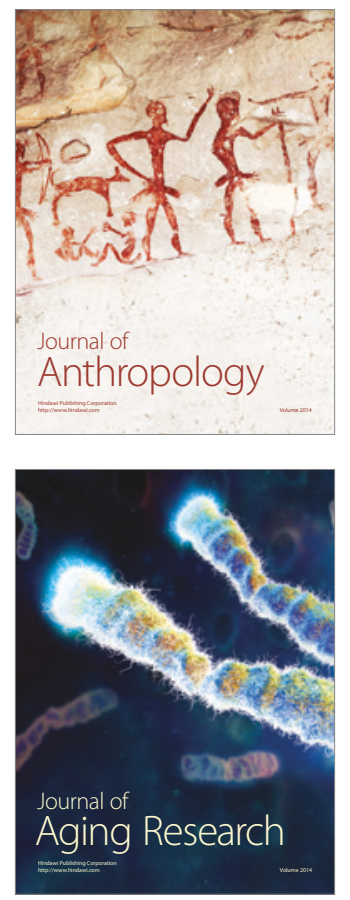
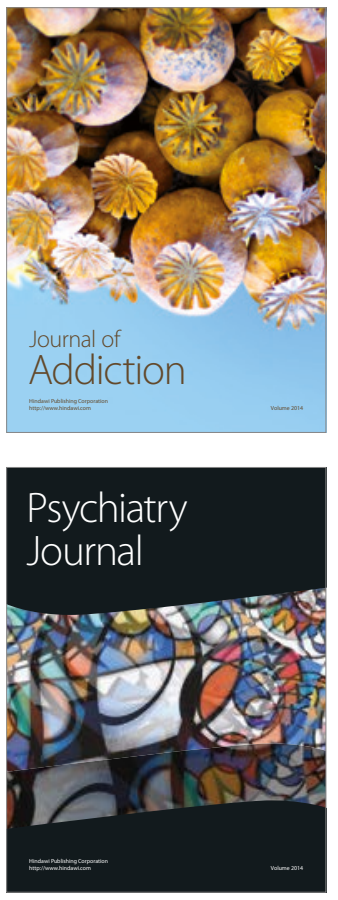

Child Development

Research

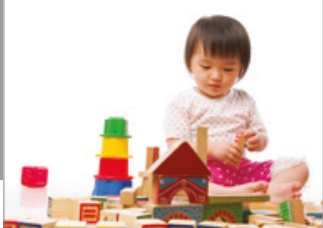

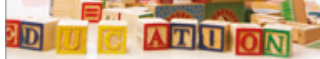
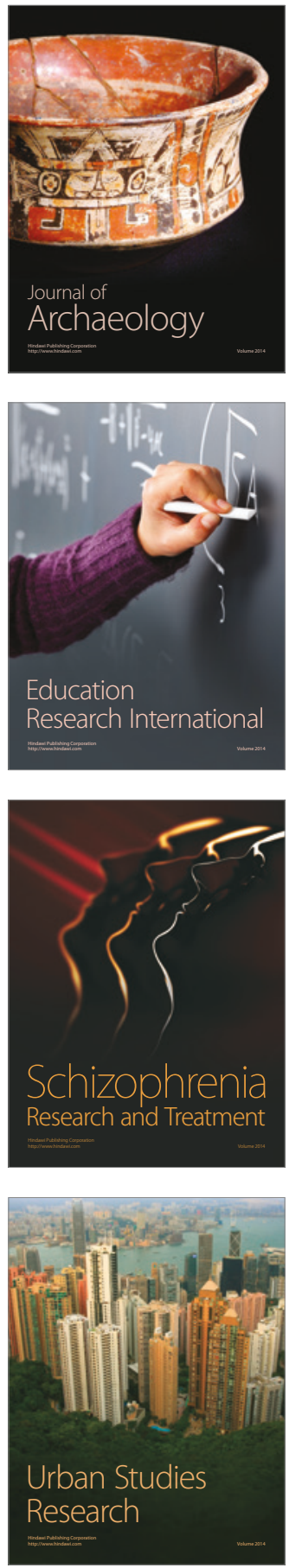